säure ermöglicht, sondern dass eine specifische Einwirkung des Lösungsmittels auf die Borsäure die Voraussetzung für die Funktion der Verbindung $\mathrm{H}_{3} \mathrm{BO}_{3}$ als einbasische Säure bildet.

Wenn die Annahme richtig jst, dass das Glycerin und der Mannit infolge ibres hohen Gehaltes an Hydroxylgruppen durch ihre Gegenwart die schwache Borsäure befähigen als vollwerthige einbasische Säure zu wirken. so ist vielleicht der Schluss zulässig, dass der Vethylalkohol diese Funktion deshalb eher übernehmen kann als der Aethylalkohol, weil in seinem Molekül die Hydroxylgruppe weit mehr in den Vordergrund tritt als in dem des Aethylalkohols; die Konstitution der drei wirksamen Verbindungen ist insofern ähnlich, als nach unseren jetzig $\curvearrowright n$ Anschauungen in ihnen jedes rorhandene Kohlenstoftatom mit einer Hydroxylgruppe in direkter Verbindung steht.

Meine sehr beschränkte freie Zeit machte es mir leider unmöglich, die in manchen Punkten vorhandenen Liicken dieser Cntersuchungen auszufüllen. Derselbe Grund zwingt mich auch, ron der weiteren Verfolgung der sich ergebenden Fragen theoretischer Natur Abstand zu nehmen.

\title{
Beiträge zur Kenntniss von der Widerstandsfähigkeit der Pflanzenalkaloïde gegen Fäulniss.
}

\author{
Von \\ Dr. Theodor Panzer, Assistent. \\ Mittheilung aus dem Universitatslaboratorium für medicinische Chemie \\ in Wien.
}

Unsere Kenntnisse über das Verhalten bezw. die Beständigkeit der Pflanzenalkalöde in faulenden Stoffen, insbesondere in faulenden Leichentheilen, verdanken wir zum weitaus grössten Theile zahlreichen Untersuchungen, welche sich auf das widerstandsfähige Strychnin beziehen. Von diesen Cntersuchungen seien nur die von Macadam, Cloëtta, Dragendorff, Erdmann und Uslar, Riecker, Heintz, Wolff, Ipsen und ron Noyes genannt, welche zweifellos ergeben haben, dass das Strychnin in faulen Leichentheilen noch lange Zeit (bis gegen 3 Jahre) nach dem Ableben des rergifteten Lebewesens nachzuweisen ist, wenn dieses Gift nicht durch einen Auslaugungsprocess aus der rerfaulten Masse entfernt wurde.

Es geht selbstrerständlich nicht an, die für das Strychnin gewonnenen Erfahrungen ohne Weiteres zu verallgemeinern, d. h. auch für jedes andere Pflanzenalkaloïd zu verwerthen, denn bei der verschiedenen chemischen Konstitution der in die Gruppe der Pflanzenalkaloïde gehörenden Verbindungen wäre es ja möglich, dass hinsichtlich der Beständigkeit derselben gegen die Fäulniss 
wesentliche Unterschiede bestehen. Man wird daher, wenn es sich darum handelt, die Beständigkeit des einen oder des anderen Alkaloïdes zu beurtheilen, für jedes derselben besondere Untersuchungen anzustellen lıaben. Es finden sich zwar vereinzelte Angaben über die Widerstandsfähigkeit anderer Alkaloïde gegen Fäulniss in der Litteratur, aber sie sind doch ziemlich späriich.

Ueber das Morphin schreibt Dragendorff folgendes: "In feuchten Gemischen mit anderen organischen Stoffen hält sich das Morphin einige Wochen lang “i ${ }^{\text {1). }}$.

Dieser Angabe kann ich zwei Beobachtungen hinzufügen, welche, wie ich glaube, einen willkommenen Beitrag zur Kenntniss des Verhaltens des Morphins gegenüber der Fäulniss bilden. Es standen mir nämlich die Leichentheile ron zwei Selbstmördern zur Verfügung, deren Leichen sanitätspolizeilich obducirt und dann von Herrn Hofrath Professor Dr. E. Ludwig und mir chemisch untersucht wurden. In den frischen Leichentheilen, und zwar in dem einen Falle: Magen sammt Inhalt, ein Stück IDünndarm, I)ickdarm, Niere, Leber und Harn, in dem zweiten Falle: Jagen sammt Inlaalt, oberer Dünndarm, Leber und Niere, wurden nennenswerthe Mengen von Morphin nachgewiesen.

Die bei dieser Untersuchung nicht rerbrauchten Reste der Leichentheile wurden nun mit etwas Wasser übergossen und in einem locker bedeckten Becherglase 6 Monate lang (von Ende Juni bis Lnde I)ecember 1900) bei Zimmertemperatur stehen gelassen, so dass das Gemenge eine hochgradige Fäulniss durchmachte.

Jie gefaulten Massen jeder der beiden Leichen wurden getrennt verarbeitet, zunächst mit Wasser verdünnt, mit Weinsäure angesäuert und einige Stunden auf dem Wasserbade gelinde erwärmt. Nach dem Erkalten wurde filtrirt, das Filtrat vorsichtig auf dem Wasserbade zur Syrupdicke verdunstet und der Rückstand solange mit Alkohol versetzt, bis kein Niederschlag mehr entstand. Die von der Fällung abfiltrirte alkoholische Flüssigkeit wurde sodann durch Frwärmen auf dem Wasserbade vom Alkohol befreit, der $\Lambda$ bdampfrückstand mit Wasser aufgenommen, die Lösung von dem Lngelösten durch Filtration getrennt und das sauer reagirende Filtrat mit Aether ausgeschütelt. Die wässerige Flüssigkeit, im Scheidetrichter von der Aetherschicht abgezogen, wurde mit Kalilauge alkalisch gemacht und mit einer neuen Menge Aether ausgeschüttelt. Nach der Trennung von dieser ätherischen Lösung wurde die Flüssigkeit mit Salzsäure angesäuert, mit Ammoniak bis zur alkalischen Reaktion

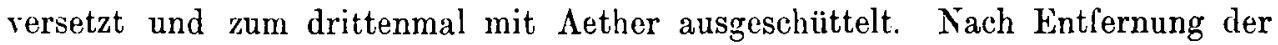
Aetherschicht wurde endlich der so vorbereiteten Flüssigkeit das Morphin durch Ausschütteln mit Amylalkohol entzogen.

Die drei Aetherausziige wurden unbeachtet gelassen. Der Amylalkohol von der vierten Ausschüttelung hinterliess in jedem der beiden Fälle eine beträcht-

1) Dragendorff, Die gerichtlich-chemische Ermittlung von Giften. 4. Aufl. Göttingen 1895 , s. 227 . 
liche Nenge einer hellbraunen, schmierigen Masse, die selbstrerständlich zur Anstellung der Specialreaktionen auf Ilorphin vollkommen ungeeignet war. Aus dieser schmierigen Masse musste daher das Morphin erst in möglichst reinem Zustande ausgeschieden werden.

$\mathrm{Zu}$ diesem $\mathrm{Zwecke}$ wurden diese Abdampfrückstände mit verdünnter Salzsäure in der Kälte ausgezogen und die so erhaltene saure Fliissigkeit mit Amylalkohol ausgeschüttelt, welcher fast die gesammte braunfürbende Substanz aufnahm. Die rom Amylalkohol getrennte wässerige Lösung wurde hierauf mit Ammoniak alkalisch gemacht und mit Essigäther, der kurz vorher mit Wasser gewaschen worden war, ausgeschüttelt. Der von der wässerigen Flüssigkeit getrennte Essigäther hinterliess bei freiwilligern Verdunsten einen amorphen Rückstand, welcher sich in verdiunnter Salzsäure vollständig löste. Die salzsaure Lösung schied beim Stehen in dem ersten Falle bald farblose Nadeln ab, in dem zweiten Falle konnte dieses Ergebniss erst durch Anwendung ron etwas reiner Thierkohle erreicht werden.

In beiden Fällen zeigten diese Krrystalle nach dem Abpressen der Mutterlauge die folgenden Reaktionen:

1. Eine mit rerdïnnter Salzsäure bereitete Lösung gab mit Kaliumquecksilberjodid, mit Phosphorwolframsäure und mit Jodjodkalium reichliche Niederschläge.

2. Eine Lösung der Krystalle in koncentrirter Schwefelsäure erwärmt, gab nach dem Erkalten auf Zusatz eines Tropfens koncentrirter Salpetersäure eine intensiv blutrothe Färbung.

3. Eine koncentrirte wässerige Lösung der Krrystalle wurde auf Zusatz von Eisenchlorid blau.

4. Die farblose Auflösung der Krystalle in Wasser, mit einer wisserigen Jodsäurelösung versetzt, wurde schwach gelb; beim Schiitteln dieser Flüssigkeit mit Chloroform nahm die Chloroformschicht eine röthliche Färbung an.

Es ist also in beiden Fällen gelungen, aus den 6 Monate lang der Fäulniss ausgesetzten Leichentheilen unverändertes Morphin als salzsaure Verbindung im reinen Zustande abzuscheiden, und es geht aus diesen Ergebnissen hervor, dass Morphin einige Monate lang der Fäulniss widerstehen kann. Durch die Gegenwart grosser Mengen ron Fäulnissstoffen wurde die Abscheidung, bezw. Reindarstellung des Morphins gegenüber solchen Fällen, in denen die Leichentheile frisch zur Cntersuchung lommen, sehr erschwert. 